Department of Pathology \& Clinical Pathology

Faculty of Veterinary Medicine, Assiut University

Head of Dept.: Prof. Dr. M. I. El-Sherry

\title{
PATHOLOGICAL CHANGES OF THE REPRODUCTIVE TRACT OF LAYING HENS AND THEIR CAUSATIVE AGENTS
}

(With 2 Tables and 22 Figures)

\author{
By \\ M. MUBARAK; A.M. ABD-EL GAWAD* \\ and A.F. BASTAWROUS* \\ *: Animal Health Research Institute, Assiut. \\ (Received at 29/9/1998)
}
مستح على الإصابات الباثولوجية للقنوات التناسلية للاجاج البياض المبلة

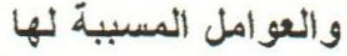

$$
\begin{aligned}
& \text { محمد مبارك محمد ، عبل التواب محمد عبل الجو/د }
\end{aligned}
$$

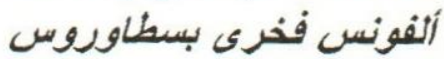

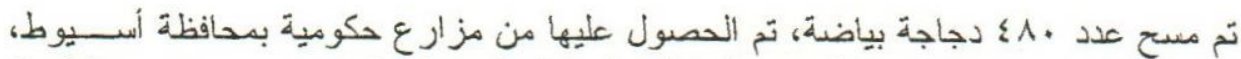

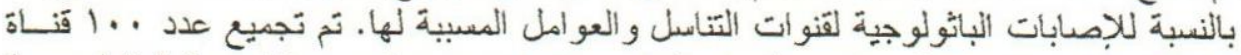

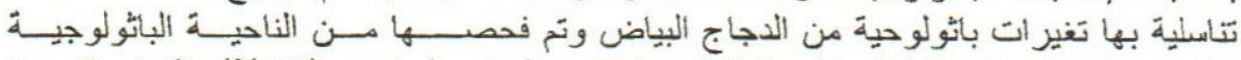

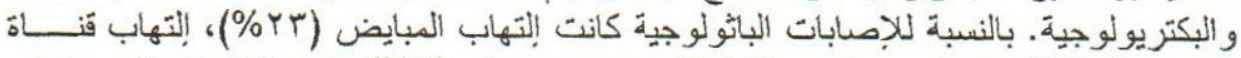

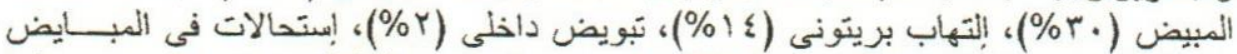

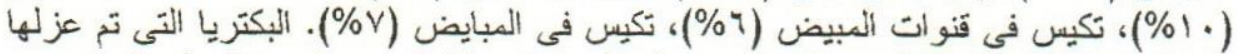

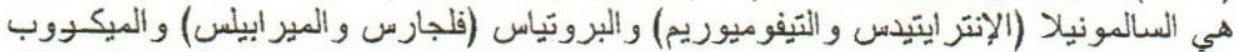

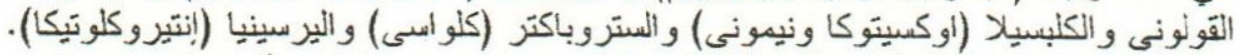

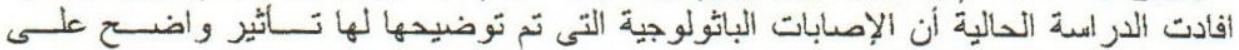

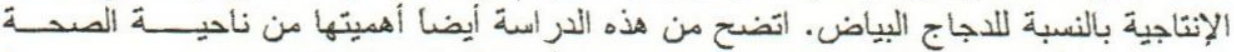

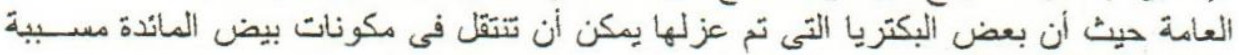
بعض الأمر اض اضل اللغنسان. 


\section{SUMMARY}

A total of 480 freshly dead laying hens procured from local governmental farms at Assiut Governorate were surveyed for the pathological affections of the reproductive tract and their causative agents. Grossty abnormal 100 reproductive tracts were collected and examined pathologically and microbiologically. The main types of pathological changes were: Oophoritis (23\%), salpingitis (30\%), egg peritonitis $(14 \%)$, egg bound $(4 \%)$, internal laying $(2 \%)$, ruptured oviduct $(2 \%)$, degenerated ovarian follicles $(10 \%)$, cystic oviducts $(6 \%)$ and cystic ovaries $(7 \%)$. The isolated bacterial agents were : Salmonella enteritidis, Salmonella typhimurium, Proteus vulgaris, Proteus mirabilis, Escherichia coli $\left(\mathrm{O}_{86}: K_{61}\right)$, Klebsiella oxytoca, Klebsiella pneumoniae, Citrobacter cloacae and Yersinia enterocolitica. No viral agents were recovered from the examined reproductive tracts. The obtained data indicate that the demonstrated pathological changes have adverse effects on the productivity of the laying hens. Moreover, the present study has a public health importance as some of the isolated bacterial agents can be transmitted in the contents of table eggs.

Key Words: Reproductive tract, laying hens, pathology, causative agents.

\section{INTRODUCTION}

Egg production and the related problems remain as a main subject of poultry researches. Poultry producers do their best to prevent or control any disease condition that may affect the rate of egg production. Any decline in egg production results in great economic losses especially in the large integerated farms. Also, some affections of the reproductive tract may lead to some mortalities in the laying fowls (Randall et al., 1977 and Jones et al., 1978).

Terms such as oophoritis, salpingitis, prolapse of the oviduct and salpingo-peritonitis have been used to describe the pathological affections of reproductive tract of laying hens (Gross and Siegel.1959; Suganuma, 1960; Domermuth and Gross, 1962; Batra et al., 1982 and Lester, 1988).

Some aetiological agents (bacterial and viral) were found to cause various pathological changes in the reproductive tract of laying hens and others have the tendency to localize in the ovaries or in acertain segment 
of The oviduct (Sevoian and Levine, 1957; Crinion et al., 1971 a \& b; Van Eck et al ., 1978; Batra et al., 1982; Kohler et al., 1982; Bygrave and Gallagher, 1989 and Snoeyenbos, 1991).

Many aetiological agents have been isolated from cases of salpingitis and oophoritis. The most frequently isolated bacterial organisms were E.Coli (Pradhan and Nayak, 1973; Bisgaard, 1995) and Proteus mirabilis (Bisgaard and Dam, 1981). Salmonella typhimurium (S.typhimurium) and Salmonella enteritidis (S. enteritidis) are known to have the ability to invade and localize in the reproductive tract of laying hens (Keller tㅡ al., 1995). Thus, these organisms represent a threat to the public health as they are able to contaminate the table eggs either during egg formation or after oviposition (Faddoul and Fellows, 1966; St. Louis et al., 1988 and Keller et al., 1995).

The purpose of the present study was to survey the pathological affections of the reproductive tract of laying hens and their causative agents. As far as we aware, information concerning the pathology and aetiology of the reproductive tract affections of laying hens is sparse in Egypt. Therefore, the present work was undertaken to study these affections under the local conditions.

\section{MATERIALS and METHODS}

\section{* Collection of Samples:}

A total of 480 dead laying hens were surveyed in the present study over a period extending from October, 1997 to August, 1998. The samples were procured from governmental farms at Assiut Governorate. One hundred reproductive tracts (ovaries and oviducts) from these freshly dead laying hens were collected. Only reproductive tracts with gross pathological changes were represented

Laying hens in the surveyed farms aged between 30-45 weeks The relevant flocks experienced increased mortality rates, drop in egg production and increased number of soft-shelled eggs.

\section{* Histopathology:}

Specimens from the ovaries and pieces from different segments of oviduct (infundibulum, magnum, isthmus, uterus and vagina) were fixed in $10 \%$ neutral buffered formalin and processed routinely for paraffin embedding technique. Tissue specimens were dehydrated in ascending grades of ethanol, cleared, embedded in paraffin wax and sectioned at 3 


\section{Assiut Vet. Med. J. Vol. 40 No. 79 . October 1998.}

$\mu$. Tissue sections were stained with haematoxylin and eosin (HE) according to the method described by Bancroft and Stevens (1982).

* Isolation of micro-organisms:

\section{Isolation of Salmonellae}

\section{(i) Ovaries}

Yolk was collected on sterile swabs from the interior of the ovules after the exterior was sterilized by searing with a hot spatula. The swabs were placed in $10 \mathrm{ml}$ Selenite "F" broth

\section{(ii) Oviducts:}

The exterior of the oviducts was sterilized by dipping in $70 \%$ alcohol and flaming over a burner. Two grams from each oviduct were cut into small pieces with sterile scissors. The pieces of each oviduct were cultured in $10 \mathrm{ml}$ Selenite "F" broth.

Selenite cultures from ovaries and oviducts were incubated at $37^{\circ} \mathrm{C}$ for 18 hours. Approximatelly 3 loopfuls of broth were then streaked on three specific selected solid media (MacConkey, brilliant green and SS agar plates) and incubated overnight at $37^{\circ} \mathrm{C}$. Salmonellalike colonies (non-lactose fermenters) were further identified morphologically and biochemically according to the methods of Koneman et. al (1994) and Quinn et. al (1994). Isolates that produced biochemical reactions simulating Salmonellae were subjected to serological identification as described by Edward and Ewing (1972) and the instructions of the manufacturer laboratory (Anon, 1975). The final decission of typing was made according to the scheme of Kauffmann (1972).

\section{2- Isolation and identification of other members of Enterobacteriaceae:}

Cotton Swabs from the oviducts and interior of ovules were aseptically inoculated into tubes of tryptose broth. The tubes were incubated at $37^{\circ} \mathrm{C}$ for 24 hours. Loopfuls of the broth were streaked on brilliant green and MacConkey's agar plates in a way to obtain separate colonies and incubated at $37^{\circ} \mathrm{C}$ for 24 hours. Different colonies of both lactose and non-lactose fermenting bacteria were picked up into nutrient agar slants for further purification and identification. This was made according to the methods of Koneman et al (1994) and Quinn et al (1994). Serological identification of the isolates that produced biochemical reactions simulating E.coli was carried out after their purification. Identification was done by determination of " $\mathrm{O}$ " and " $\mathrm{K}$ " group antigens using slide agglutination test using $E$. coli antisera 
available commercially (AG.Marburg, W.Germany) and following the instructions of the manufacturer. Other organisms of Enterobacteriaceae were identified on the basis of their biochemical reactions as their respective immune sera were not available.

\section{3- Isolation of Pasteurella haemolytica:}

Cotton swabs from the ovaries and oviducts were plated on blood agar containing 10\% sheep RBCs and MacConkey Agar. The culture plates were incubated aerobically for 24 hours at $37^{\circ} \mathrm{C}$. The isolates were identified according to morphology and biochemical characteristics (Carter and Cole, 1990).

\section{4- Virus isolation:}

Suspensions $(10 \% \mathrm{w} / \mathrm{v})$ were made in phosphate buffered saline (PBS) from portions of ovaries and oviducts of affected hens. Samples were centrifuged at $4000 \mathrm{rpm}$ for 20 minutes. Five 8-day-old chicken embryos were inoculated via allantoic sac with $0.1 \mathrm{ml}$ of the bacterial free supernatant fluid. All embryos were incubated and held for 6 days.

Embryos were candled and fluids were harvested and tested for haemagglutination activity (Yamaguchi et al., 1981).

\section{RESULTS}

\section{Gross Pathology:}

All the studied reproductive tracts showed gross abnormalities. Gross picture of the ovaries was suggestive of either inflammatory or degenerative changes. The degenerated ovarian follicles were mis-shaped and characterized by resorption of yolk and roughness of their surfaces. Some other follicles were congested or haemorrhagic and showed brownish discoloration (Fig. 1).

The contents of these follicles were either caseated or oily materials. Cases with gross signs of egg peritonitis, revealed fibrinous material deposited over the surface of ovarian follicles which were adhesed to each other (Fig. 2). In these cases, yolk material was seen free in the peritoneal cavities. Some ovaries showed atrophied and discolored follicles which were collapsed and had stalk-like attachments to the ovarian base (Figs. 3 and 4). Ovaries with cystic changes had degenerating follicles containing watery fluid. Firm cauliflower growths were noticed in some ovaries.

Oviducts, with suggestive inflammatory changes, had thickened and edematous walls with luminal casteated material. Other oviducts had 
haemorrhagic mucosa and contained purulent material. Oviducts with egg bound had lodged egg in their lumina and the surface of bound egg was covered by cheesy material. Mucosal bulging cysts were noticed in some oviducts. Ruptured oviducts were observed in some cases and caseated adhesive material was seen at site of rupture. Vaginal prolapse was a gross feature in some cases. Internal laying was a feature in cases with oviducts occluded with caseated luminal material. In these cases, semicalcified eggs were attached to mesentry. In cases with gross signs suggestive of oophoritis and salpingitis, there was edema of the mesosalpinx and ovarian ligaments.

\section{Histopathology:}

The encountered general histopathological changes were as follows:

\section{Ovary:}

Degeneration of mature and immature follicles was noticed in many cases. Yolk vacuolation was one of the follicular degenerative changes and it was related to the degree of degeneration. In the degenerated follicles, granulosa cells were either separated from the yolk material or swollen with irregular outline. Occasionally, these cells were shrunken or flattened. Irregular spaces were seen between the granulosa cells and the underlying basement membrane or between the latter and theca interna (Fig. 5).

Fatty vacuolation was less frequent between granulosa cells (inter granulosal vacuolation). The contents of the degenerated follicles varied and involved various-sized yolk spherules and debris including desquamated granulosa cells (Fig. 6). Haemorrhages (Fig. 7) and macrophages phagocytozing yolk material or haemosiderin (Fig. 8) were also observed. The degenerative changes were more apparent in the mature follicles while the primary follicles showed necrotic changes (Fig. 9). At the vicinity of the degenerated follicles, heterophil granulocytes were usually observed (Fig10). The infiltrating heterophils were seen extending to theca interna and occasionally they were intrafollicular. Ovarian stroma (cortical stroma) bordering the thecal layers was also infiltrated with granulocytes (Fig. 11). In some ovariaes, the granulocytic infiltration was so extensive that the ovarian architecture was masked in some locations. The cellular infiltration was also extended to the surface germinal epithelium (Fig. 12). Irregular masses of yolk material were 
frequently observed at site of necrosed follicles (Fig. 13) and nearby the degenerating ones (Fig. 14). In ovaries with marked cellular infiltration, the cortical capillaries were distended and cortical arterioles showed medial vacuolation and advenential and perivascular edema (Fig. 15). The stroma in these areas was edematous and loose. Lymphoid cell infiltration was noticed in few ovaries surrounding the degenerating follicles (Fig. 16). However, this infiltration showed no tendency to form follicular structures. Proliferating fibroblasts surrounding thecal layers of some follicles were also observed.

\section{Oviduct:}

\section{a- Infundibulum:}

Edema in lamina propria and scattered lymphoid cells in muscularis and corium were the histological findings seen in most cases.

\section{b- Magnum:}

Submucosal glands were dilated and contained deeply eosinophilic material. Glandular epithelium showed various necrobiotic changes. Interglandular capillaries were distended and the edematous changes extended from lamina propria to mesothelium. Some oviducts had magnal heterophilic cell infiltration which involved the interglandular areas and extended to mucosal epithelium. Some cases showed complete sloughing of the covering epithelium, edema of the whole magnal layers, extravasated erythrocytes in mucosa and submucosa and diffuse heterophilic infiltration (Fig. 17). Other cases of salpingitis showed similar features with occlusion of the magnal lumen with fibrinopurulent exudate (Fig. 18) or masses of necrosed heterophils (Fig. 19). Lymphofollicular reaction was detected in some cases and this caused compression of the glandular structures (Fig. 20). Scattered lymphocytes were seen in perivascular locations in some oviductal samples.

\section{c- Isthmus}

Cystic dilation of the glandular structures was an infrequent observation and oversecretion of ovokeratin material was noticed in some isthmus glands. In many cases, there were intertubular hyperaemia and edema. Marked heterophilic cell infiltration was a histological feature in some cases. The infiltrating heterophils were chiefly seen in glandularis 


\section{Assiut Vet. Med. J. Vol. 40 No. 79, October 1998.}

(interglandular and even intraluminal in some glandular structures). Heterophils were also seen infiltrating the mucosal epithelial lining.

\section{d- Uterus}

Edema separating the packed tubular glands was observed frequently in the uterine corium. In mucosa and submucosa, pericapillary haemorrhages were also a frequent finding. Uterine glands, in many uteri, were either cystically dilated or less frequently atrophied. The dilated glands were distended with lightly eosinophilic material and had flattened epithelium. Foci of glandular necrosis were evidenced by the disrupted and disintegrated glandular epithelium with the presence of chromatin debris at sites of necrosed glandular structures. Covering mucosal epithelial cells were vacuolated and many of them lost their integrity and some were desquamated. Heterophilic infiltration was extensive in some examined uteri and involved glandularis or even the mucosal covering epithelium. Epithelial basement membranes were indistinct in some locations due to heavy cellular infiltration. Complete destruction of mucosa and submucosa, which were replaced by tissue debris and masses of necrosed heterophils, were noticed in some uteri (Fig. 21).

Some uteri were denuded from their mucosa and their lumina contained caseated material admixed with heterophils and necrosed epithelial cells (Fig.22).

\section{e- Vagina:}

Edematous changes of corium (corium of vaginal folds) were outstanding especially in cases with gross vaginal prolapse. Also, these cases had diffuse heterophil cell infiltration in the corium and in the covering mucosal epithelium (intra-epithelial infiltration). Focal epithelial necrosis was also observed in these cases.

Table (1) shows summary of the gross and microscopic features of the studied ovaries and oviducts.

\section{Isolation:}

The results for isolation and identification of bacterial agents were summarized in Table (2). No viral agents were recovered from the examined reproductive tracts. 


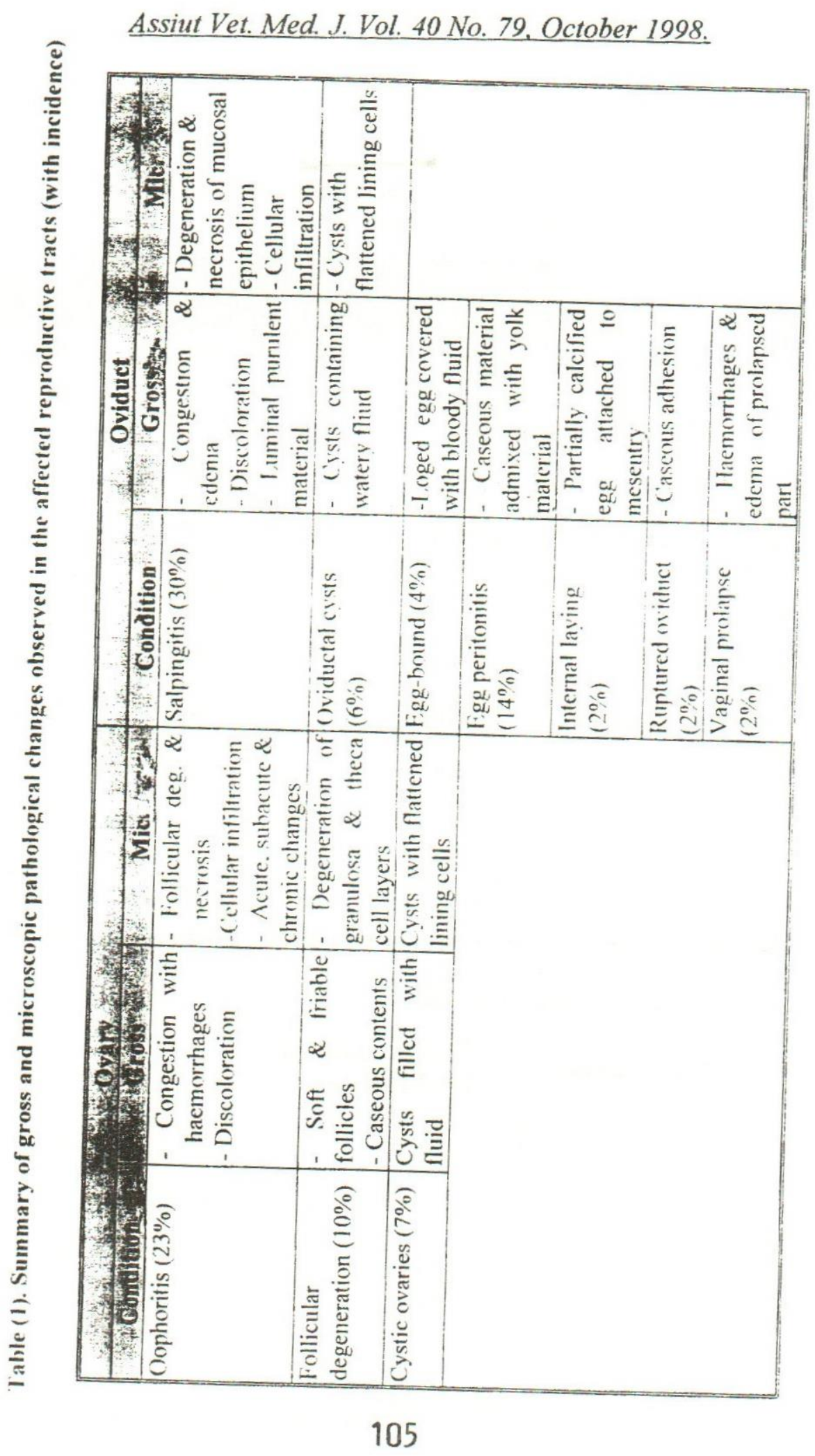


Table 2. Incidence and frequency of the bacterial agents isolated from the affected reproductive tract of laying hens

\begin{tabular}{|c|c|c|c|c|}
\hline \multirow[b]{2}{*}{ tsoliate } & \multicolumn{2}{|c|}{ ( } & \multicolumn{2}{|c|}{ 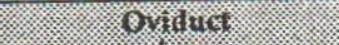 } \\
\hline & 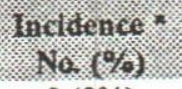 & Frefuchis: & Hinctience & 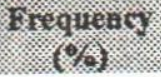 \\
\hline Salmonella enteritidis & $3(3 \%)$ & 11.5 & $6(6 \%)$ & 16.7 \\
\hline Salmonella typhimurium & $2(2 \%)$ & 7.7 & $7(7 \%)$ & 19.4 \\
\hline Proteus vulgaris & $3(3 \%)$ & 11.5 & $0.0(0.0 \%)$ & 0.0 \\
\hline Proteus mirabilis & $0.0(0.0 \%)$ & 0.0 & $7(7 \%)$ & 19.4 \\
\hline E. Coli $\left(O_{86}: K_{61}\right)$ & $2(2 \%)$ & 7.7 & $3(3 \%)$ & 8.3 \\
\hline Klebsiella oxytoca & $9(9 \%)$ & 34.6 & $4(4 \%)$ & 11.1 \\
\hline Klebsiella pneumoniae & $2(2 \%)$ & 7.7 & $5(5 \%)$ & 13.9 \\
\hline Citrobacter cloacae & $2(2 \%)$ & 7.7 & $2(2 \%)$ & 5.6 \\
\hline Yersinia enterocolitica & $3(3 \%)$ & 11.5 & $2(2 \%)$ & 5.6 \\
\hline Total isolates & 26 & & 36 & \\
\hline
\end{tabular}

* Total number of samples $=100$

** Frequency $=\frac{\text { Positive isolate }}{\text { total isolates }}$ 


\section{DISCUSSION}

In the present study, the pathological changes of reproductive tract represented $20.8 \%(100 / 480)$ of the tissue lesions in the surveyed laying hens. The encountered pathological changes included: Oophoritis $(23 \%)$, salpingitis (30\%), egg peritonitis (14\%), egg bound ( $4 \%)$, internal laying $(2 \%)$, ruptured oviduct $(2 \%)$, degenerated ovarian follicles $(10 \%)$, cystic oviducts $(6 \%)$ and cystic ovaries $(7 \%)$.

It has been postulated that the high estrogenic activity in the laying hens predispose them for various reproductive infections (Riddell, 1987 and 1996). The source of estrogen is the rapidly growing and ovulating follicles. The present cases were obtained from flocks at the peak of egg production. Therefore, it is reasonable to presume that these birds had elevated estrogenic activity and thus they were susceptible for reproductive tract infections.

The demonstrated pathological ovarian and oviductal lesions in the present cases apparently caused various degrees of tissue destruction in the reproductive tract. The illustrated ovarian changes in our cases, which involved both growing and mature follicles, ultimately affect the ovulation rate and subsequently the rate of egg production. The oviductal changes in the present birds involved all segments of the oviduct which implies formation of abnormal egg contents. In the present cases, some of the observed oviductal lesions, especially the necrotizing salpingitis, undoubetdly lead to cessation of egg production as they cause destruction of the oviduct. Cases of peritonitis observed in the present birds were probably related to oviductal dysfunction. It has been shown that dysfunctions of the ovary and oviduct may interfer with the passage of ova and lead to abdominal ovulation with subsequent extensive peritonitis (Gross and Siegel, 1959 and Pradhan and Nayak, 1973).

In the present cases, features of oophoritis were observed at the incidence rate of $23 \%$ and Salmonellae were isolated from these cases. Oophoritis is known to be a prominent feature of Salmonella infection (Lester, 1988; Bygrave and Gallagher, 1989 and Snoeyenbos, 1991). Infiltration of follicular wall and yolk by heterophils is a histological feature of salmonella infection (Suganuma, 1960 and Snoeyenbos et al., 1969). Focal and diffuse heterophil cell infiltrations in ovaries and oviducts were observed in laying hens naturally infected with S.enteritidis (Hoop and Pospischil, 1993). In this respect, S. enteritidis has the ability 
to invade the reproductive tract after passing the epithelial lining and it's mobilization to the deeper layers is carried out by tissue macrophages (Riddell, 1996).

In many ovarian samples, we noticed free yolk material in the stroma of the affected ovaries. Yolk material was likely released from degenerated or bursting follicles. Bursting follicular atresia is common in laying hens exposed to stresses or infectious diseases (Riddell, 1996). On rupture of the thecal wall of degenerated follicle, the yolk material escapes into abdominal cavity, or retained within the ovary. Free yolk material in the abdominal cavity, in the presence of secondary infection, leads to peritonitis (yolk peritonitis) (Riddell, 1987). This may explain the present cases of peritonitis which were also accompanied by picture of oophoritis. Alternatively, yolk peritonitis may arise from ascending oviductal infection as in case of coliform salpingitis (Batra et al., 1982 and Bisgaard, 1995). In this case, bacteria grow rapidly in the free yolk leading to peritonitis (Gross and Siegel, 1959). Bacteria associated with salpingitis in chickens include E. coli (Smith et al., 1985) which was isolated from the present cases at the incidence of $2 \%$. The distention of oviducts with caseous material, as ovserved here, is regarded as an evidence of E.coli-mycoplasma mixed infection (Nakamura et al., 1992) Also, distention of oviductal lumen by a core of necrotic purulent material, as demonstrated here, was usually described in coliform infection (Randall and Reece, 1996).

Some of the present cases showed lymphofollicular reaction in the oviduct which may be indicative of viral infection. IB-virus causes similar lesion in association with destruction of the oviductal epithelium ( Crinion et al., 1971 a \& b). The absence of intranuclear inclusions in the examined uterine epithelium may exclude the possibility of adenovirus infection (Egg-drop syndrome-76) (Van Eck $\underline{\text { et }}$ al., 1978; Yamaguchi et al., 1981 and Kohler et al., 1982). However, no viral agents were isolated from the studied reproductive tracts.

Some members of family Enterobacteriaceae are considered as the most important agents which infect poultry. These organisms cause great mortalities and various morbidity changes. Moreover, they result in economical losses in poultry industry due to their negative influence on egg production, either the quantity or quality of eggs. In this respect, salpingitis was recorded in cases of E.coli and Proteus mirabilis infections (Bisgaard and Dam, 1981 and Bisgaard, 1995). Salmonellae were isolated from the ovaries and oviducts in the present study. These 


\section{Assiut Vet. Med. J. Vol. 40 No. 79, October 1998.}

organisms were identified serologically as S.enteritidis and $S$. typhimurium. The isolation rate of $S$. enteritidis and $S$. typhimurium was higher from the oviducts than that from the ovaries. This result substantiates the findings of previous workers (Snoeyenbos et al., 1969; Snoeyenbos, 1991 and Thiagarajan et al., 1994). The more frequent isolation of S.enteritidis from the oviduct may explain the finding that S.enteritidis was isolated more often from the egg-white than from eggyolk. It was suggested that S.enteritidis can migrate through the upper oviduct into chicken eggs in association with albumin (Gast and Beard, 1990; Hoop and Pospischil, 1993 and Keller et al., 1995). Moreover, S.enteritidis is known to be the Salmonella serotype that contaminates table eggs (Shivaprasad et al., 1990). Some workers (Gast and Beard, 1990 and Bastawrous $\underline{e t} \underline{\text { al., }}$ 1997) isolated these organisms from the contents of the table eggs.

The present study indicates that S.enteritidis and S.typhimurium are capable of colonizing the reproductive tract of the laying hens. Subsequently, these organisms can be transmitted in the eggs.

The data obtained from the present cases revealed that E.coli was present at the incidence rate of $2 \%$ and $3 \%$ in the examined ovaries and oviducts, respectively. Many authors reported the negative effect of coliform infection on the reproductive tract of laying hens (Bisgaard, 1995 and Dhillon and Jack, 1996). Currently, Klebsiella oxytoca and Klebsiella pneumoniae were isolated from the ovaries with incidence of $9 \%$ and $2 \%$, respectively, while these organisms were recovered at the incidence of $4 \%$ and $5 \%$ from the oviducts. Adverse effects of Klebsiella organisms on the reproductive tract of laying chickens were reported by some investigators (EL-Atreby, 1982 and Mahalingam et al., 1988). The most common Klebsiella organisms isolated from the affected laying hens were Klebsiella pneumoniae, Klebsiella aerogenes, Klebsiella ozaenae and Klebsiella oxytoca, in order of their frequencies (Zahdeh, 1982 and Aida et al., 1993). Bastawrous et al . (1997) isolated Klebsiella oxytoca from the contents of table eggs. Therefore, we suggest that Klebsiella organisms have the ability to colonize the reproductive tract of laying hens.

Concerning Proteus organisms, Proteus vulgaris was isolated with an incidence rate of $3 \%$ from the ovaries and this organism was not recovered from the oviducts. Proteus mirabilis, on the other hand, was recovered from the examined oviducts at the incidence rate of $7 \%$. Proteus mirabilis through induction of salpingitis can affect egg 
production (Bisgaard and Dam, 1981). Proteus organisms cause also economic losses through deterioration of eggs even when kept at low temperatures (Fraizer and Westhoff, 1986). The failure to isolate $S$. pullorum may indicate that breeder hens were free from S.pullorum or the egg source was pullorum free. Organisms such as Pasteurella haemolytica, Mycoplasma gallisepticum, IB-virus and egg drop syndrome virus (EDS-virus), which are known to infect reproductive tract of laying hens (Sevoian and Levine, 1957; Domermuth and Gross, 1962 and Crinion et al., 1971 a \& b). were not isolated from the examined samples.

It is apparent that the present pathological changes have serious effects on the productivity of affected birds through destruction of the reproductive tract. The obtained data may also pay the attention to the public health importance of the present study as some of the isolated organisms can contaminate the contents of the table eggs.

\section{REFERENCES}

Aida, F.G., EL-Neklawy,E.M\& Zienab, M.Niazi (1993): Prevalence of Klebsiella in slaughtered broilers. Vet. Med. Res. Benisuef, 3 (1), 190-203.

Anon, (1975): Serological identification of Salmonellae. Difco. Laboratories, Detenoit, Michgan, U.S.A. O168.

Bancroft, D.\& Stevens, A. (1982): Theory and Practice of Histological

Techniques,2nd edn. Churchill Livingstone (Edinburgh, London, Melbourne).

Bastawrous,A.F, Khalil, N.Gh, Seddek, S.R. \& Aly, S.M. (1997): Bacteriological studies on Enterobacteriaceae isolated from table eggs in Assiut. Assiut Vet. Med. J., 36 (72), 203-214

Batra, G.L.,Singh B.Grewal. G.S, \& Sodhi S.S. (1982): Aetiopathology of oophoritis and salpingitis in domestic fowl. Indian J. Anim. Sci., 52,172-176.

Bisgaard, M.(1995): Salpingitis in web-footed birds. Prevelance, aetiology and significance. Avian pathol., 24, 443-452

Bisgaard, M. \& Dam, H.(1981): Salpingitis in poultry. II. Prevalence, bacterioology and possible pathogenesis in egg laying chickens. Nord Vet., 33,81-89 
Bygrave, A.C. \& Gallagher. J. (1989): Transmission of Salmonella enteritidis in poultry. Vet. Rec., 124-571.

Carter, G.R. \& Cole, Jr. J.R. (1990): Pasteurella and Francisella. In: Diagnostic Procedures in Veterinary Bacteriology and Mycology, 5th ed. pp. 129-142.

Crinion, R.A.P., Ball,A. \& Hofstad. M.S. (1971a): Abnormalities in laying chickens following exposure to infectious bronchitis virus at one day old. Avian Dis., 15,42-48. 1971.

Crinion, R. A. P, Ball,A. \& Hofstad. M.S. (1971b): Pathogenesis of oviduct lesions in immature chickens following exposure to infectious bronchitis virus at one day old. Avian Dis., 15,32-41. 1971.

Dhillon, A.S. \& Jack, O.K (1996): Two outbreaks of colibacillosis in commercial caged layers. Avian Dis., 40,742-746.

Domermuth, C.H. \& Gross W.B.(1962): The production of salpingitis of chickens by Mycoplasma gallisepticum. Avian Dis., 6,499-505.

Edward, P.R. \& Ewing, W.H. (1972): Inentification of enterobacteriaceae, 3rd edn.PP. 208-337. Burgeon Publishing Company, Minneapolis, Atlanta, U.S.A.

EL-Atreby, S.M.K. (1982): Studies of the microbial aetiology of dead in shell in native hatcheries. Ph. D. Thesis, Fac. Vet. Med., Assiut Univ., Egypt.

Faddoul, G.P,\& Fellows. G.W. (1966): A five-year survey of the incidence of salmonellae in avian species. Avian Dis. 10,296-304.

Frazier, W.C. \& Westhoff, D.C. (1986): Food Microbiology,6th edn. Tata Mccraw Hill Publishing Co. Ltd. New Delhi.

Gast, R.K. \& Beard C.W. (1990): Serological detection of experimental Salmonella enteritidis infections in laying hens. Avian Dis., 34,721-728.

Gross, W.B. \& Siegel. P.B. (1959): Coliform peritonitis of chickens. Avian Dis., 3,370-373.

Hoop, R.K. \& Pospischil, A. (1993): Bacteriological, Serological and immunohistochemical findings in laying hens with naturally acquired Salmonella enteritidis phage type 4 infection. Vet. Rec., 133, 391-393.

Jones, H.G.R., Randall, G.J. \& Mills, C.P.J. (1978): A Survey of mortality in three adult broiler breed flocks. Avian pathol., 7, 619628 
Kauffmann, F. (1972): Serological diagnosis of Salmonella species. Kaliffmann-White Scheme. Munksgaard, Copenhagen.

Keller, L. H., Benson, C. E. Krotec K., \& Eckroade R.J. (1995): Salmonella enteritidis colonization of the reproductive tract and forming and freshly laid eggs of chickens. Infect. Immun. 63,2443-2449. 1995.

Kohler, Van H., Loupal, G. \& Spadiut. W. (1982): Egg drop syndroms of hens. Disch. Tieraerzll Wochenschr., 89,14-16. 1982.

Koneman, E.W., Allen, S.D., Janda, W.M., Schrechen - berger, P.C. \& Winn, W.C.C. (1994): Introduction to Diagnostic Microbiology, 4th ed. P. 41. J.B. Lippincotl Campany.

Lester, S.A. (1988): Salmonella enteritidis infection in broilers \& broiler breeders. Vet. Rec., 123-350.

Mahalingam, P., Masillamony, P.R., Palaniswami, K.S. \& Venugopalan, V.T. (1988): Virulence attributes of E.coli and Klebsiella isolates from hatcheries. Indian Vet. J., 65(4), 284-287

Nakamura, K., Cook J.K.A., Frazier J.A., \& Narita. M. (1992): Escherichia coli multiplication and lesions in the respiratory tract of chickens inoculated with infectious bronchitis virus and / or E.coli. Avian Dis., 36,881-890.

Pradhan, H.K. \& Nayak, B.C. (1973): Studies on pathology of the female reproductive tract of domestic fowls. II - Experimentally induced oophoritis and peritonitis with E.coli organisms. Indian J. Poultry Sci, 8,81-86.

Quinn, P.J., Carter, M.E., Mardery, B.K. \& Carter, G.R. (1994): Clinincal Veterinary Microbiology. PP. 209-236. Year Book Wolfe Publishing. (Europ limited).

Randall, G.J., Blandford, T.B., Borland, E.D., Brooksbank, N.H., Hall, S.A., Hebert, C.N. \& Richards, S.R. (1977): A Survey of mortality in 51 Caged laying flocks. Avian pathology. 6:149-170. Randall, C.J. \& Reece, R.L. (1996): Color Atlas of Avian Histopathology. Mosby-Wolfe (London, Baltimore, Barcelona). Riddell,C. (1987): Reproductive system. In : Avian Histopathology. 1st edn. pp. 83-88. American Association of Avian Pathologists. Univ. of Pennsylvania, USA.

Riddell,C. (1996): Reproductive system. In: Avian Histopathology. $2^{\text {nd }}$ edn. pp. 211-218. American Association of Avian Pathologists. Univ. of Pennsylvania, USA. 
Sevoian, M. \& Levine P.P.(1957): Effects of infectious bronchitis on the reproductive tracts, egg production, and egg quality of laying chickens. Avian Dis., 1,136-164.

Shivaprasad, H.L., Timoney, J.F., Morales, S., Lucio, B., \& Baker, R.C. (1990): Pathogenesis of Salmonella enteritidis infection in laying chickens. I. Studies on egg transmission, clinical signs, fecal shedding and serologic responses. Avian Dis., 34,548-557.

Smith, H.W., Cook J.K.A., \& Parsell, Z.E. (1985): The experimental infection of chickens with mixtures of infectious bronchitis virus and Escherichia coli. J. Gen. Virol., 66,777-786.

Snoeyenbos, G.H. (1991): Pullorum disease. In: Diseases of poultry. 9th ed. B.W. Calnek, H.J. Barnes, C.W. Beard, W.M. Reid \& H.W. Yoder. Jr. (eds). PP. 73-86. Iowa State University Press. Ames, Iowa.

Snoeyenbos, G.H., Smyser, C.F. \& Van Rockel, H. (1969): Salmonella infections of the ovary and peritoneum of chickens. Avian Dis., 13, 668-670.

St. Louis, M. D. L., Morse, M. E., Potter, T.M., DeMelfi, J.J., Guzewich, R.V. \& P. A. Blake. (1988): The emergence of grade A eggs as a major source of Salmonella enteritidis infections. J. Am. Med. Assoc. 259,2103-2107.

Suganuma, $Y$. (1960): Histopathological studies on serositis of pullorum disease. Jpn. J. Vet. Sci. 22, 175-182.

Thiagarajan, D.A.M, Saeed, M. \& Asem, E.K.(1994): Mechanisms of transovarian transmission of Salmonella enteritidis in laying hens. Poultry. Sci., 73, 89-98

Van Eck, J. H.H., Elenbaas,L., Wensvoort,P.\& Konwenhoven (1978): Histopathological changes in the oviduct of hens producing shellless eggs associated with precipitins to adenovirus. Avian Pathol., 7,279-287.

Yamaguchi, T.S., Imada, T., Kawamura, H., Taniguchi, S., Saio, H. \& Shimamatsu, K. (1981): Outbreaks of egg drop syndrome -1976 in Japan and its aetiological agents. Avian Dis., 25,628-461.

Zahdeh, A.H.A. (1982): Studies on the problem of omphalitis in chikens. M.V. Sc. Thesis, Fac. Vet. Med., Cairo Univ., Egypt. 


\section{Assiut Vet. Med. J. Vol. 40 No. 79 . October 1998.}

\section{LEGENDS FOR FIGURES}

Fig. 1: Ovary showing mis-shaped pedunculated ova. Some ova contain caseated material (arrow) and others are congested (arrowhead).

Fig. 2: Fibrinous material deposited over the surface of ovules which are adhesed to each other (from a case showing egg peritonitis).

Fig. 3: Ovary showing mis-shaped ova which have wrinkled surface and contain oily material. Some ova (arrows) are collapsed.

Fig. 4: Ovary showing collapsed and atrophied ova. The ova are distinctly discolored and attached to the base of ovary by long stalks.

Fig. 5: Mature follicle showing separation of granulosa cell layer $(\mathrm{G})$ from the basement membrane and thecal layers. Theca inerna (I) is degenerated and theca externa (E) is infiltrated with heterophils. Ovary of 40-week-old laying hen. HE. X480.

Fig. 6: Degenerated mature follicle (F) containing cell debris and desquamated granulosa cells admixed with yolk material. Thecal layers are disrupted and follicular outline is lost. Ovary from 45week-old laying hen. HE. X480.

Fig. 7: Intrafollicular haemorrhage in the ovary of 40-week-old laying hen. Cell debris is seen accumulating at the site of necrosed granulosa and thcal cell layers. HE. X280.

Fig. 8: Degenerated follicles containing haemosiderin admixed with tissue debris. Distinction of follicular layers is lost. Irregular spaces (S) are seen separating the thecal layers. Ovary of 45 week-old laying hen. HE. X480.

Fig. 9: Immature follicle (F) showing disruption of their layers. Follicular architechture is nearly lost. Ovary of 35 -week-old laying hen. HE. X280.

Fig. 10: Heterophilic infiltration in the vicinity of a degenerated follicle. The follicular thecal layers are obviously disorganized. Ovary of 35-week-old laying hen. HE. X280.

Fig. 11: Diffuse heterophilic infiltration in the ovarian stroma. Free yolk globules $(\mathrm{Y})$ are seen admixed with the infiltrating heterophils. Ovary of 35-week-old laying hen. HE. X280.

Fig. 12: Marked heterophilic cell infiltration extending to germinal epithelium (arrow). The ovarian stroma is edematous. Ovary of 35-week-old laying hen. HE. X280. 
Fig. 13: Free yolk material (arrow) at the site of necrosed follicle. Heterophils are seen infiltrating and bordering site of necrosis. Ovary of 40-week-old laying hen. HE. X280.

Fig. 14: Yolk globule $(\mathrm{Y})$ at the vicinity of degenerated follicle which discloses disrupted granulosa cell layer. Ovary of 40 -week-old laying hen. HE. X280.

Fig. 15: Stromal arteriole (arrow) showing medial vacuolation and adventitial edema. The edematous stroma is diffusely infiltrated with heterophils. Ovary of 45-week-old laying hen. HE. X250.

Fig. 16: Ovarian stroma showing lymphoid cell infiltration. The local follicle (F) has dissociated granulosa cells which are also detached from the basement membrane. 42-week-old laying hen. HE. $\mathrm{X} 250$.

Fig. 17: Oviduct (magnum) denuded from its mucosal epithelium. Mucosa and submucosa are apparently edematous and diffusely infiltrated with heterophils. 45-week-old laying hen. HE. X280.

Fig. 18: Oviduct (magnum) revealing necrosis of mucosal epithelium. Submucosal heterophilic infiltration is also observed. The magnal lumen is filled with fibrinopurulent material (FM) admixed with epithelial debris. 40-week-old laying hen. HE. X280.

Fig. 19: Magnum showing luminal masses of necrosed heterophils (M) admixed with albuminous material. Mucosal epithelium is compressed. Oviduct of 45-week-old laying hen. HE. X280.

Fig. 20: Magnum revealing submucosal lymphofollicular reaction (LM). The glandular structures (GL) are compressed. Oviduct of 45week-old laying hen. HE. X320.

Fig. 21: Uterus of 45-week-old laying hen showing complete disruption of mucosa and submucosa which are replaced by fibrinopurulent material (FM) admixed with cell debris. Edematous changes and cellular infiltration are seen extending to muscularis. HE. X320.

Fig. 22: Uterus of 45-week-old laying hen showing epithelium-denuded mucosa which is hyperaemic and edematous. Uterine lumen is filled with lightly eosinophilic necrosed material (NM). HE.X320. 

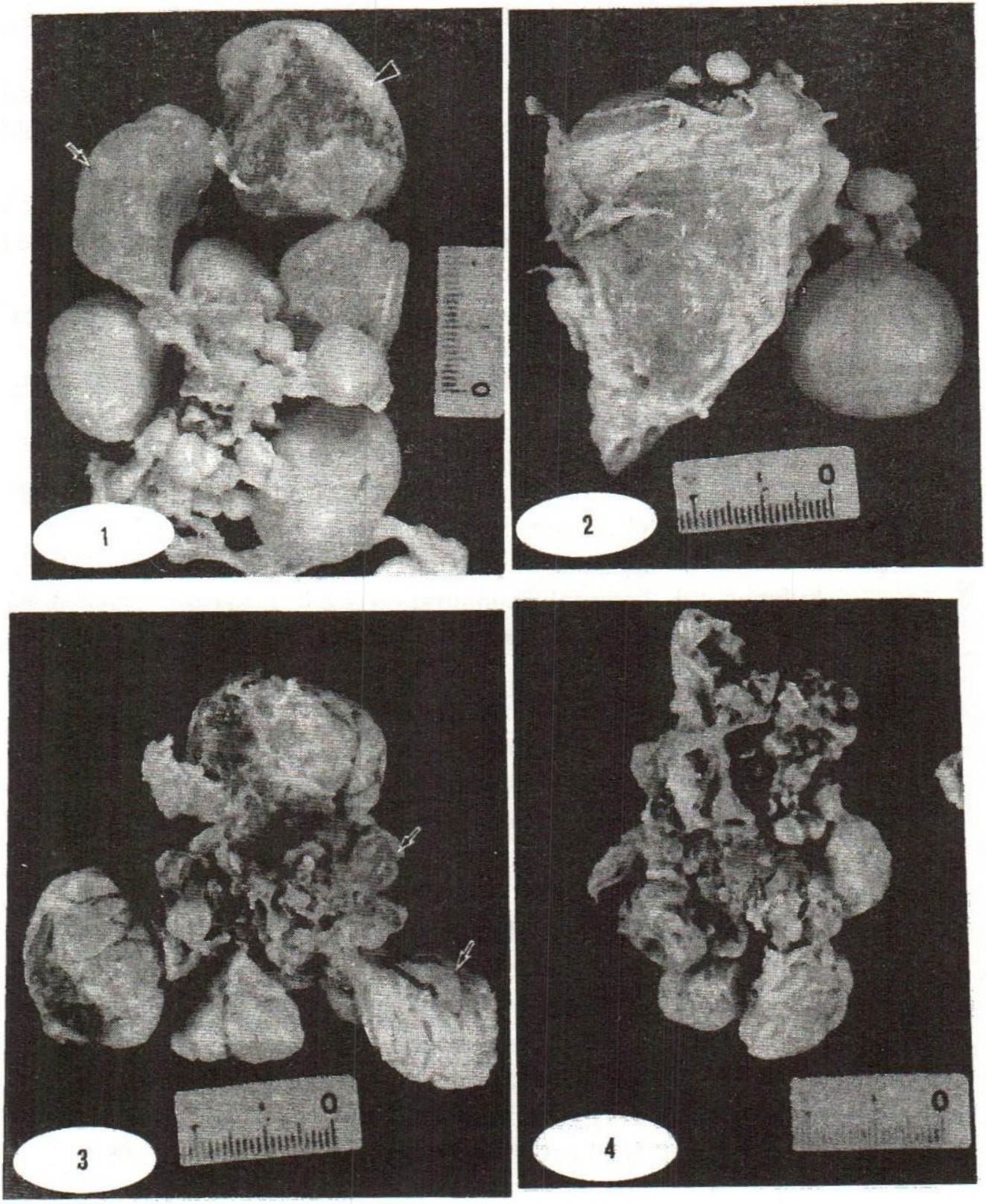

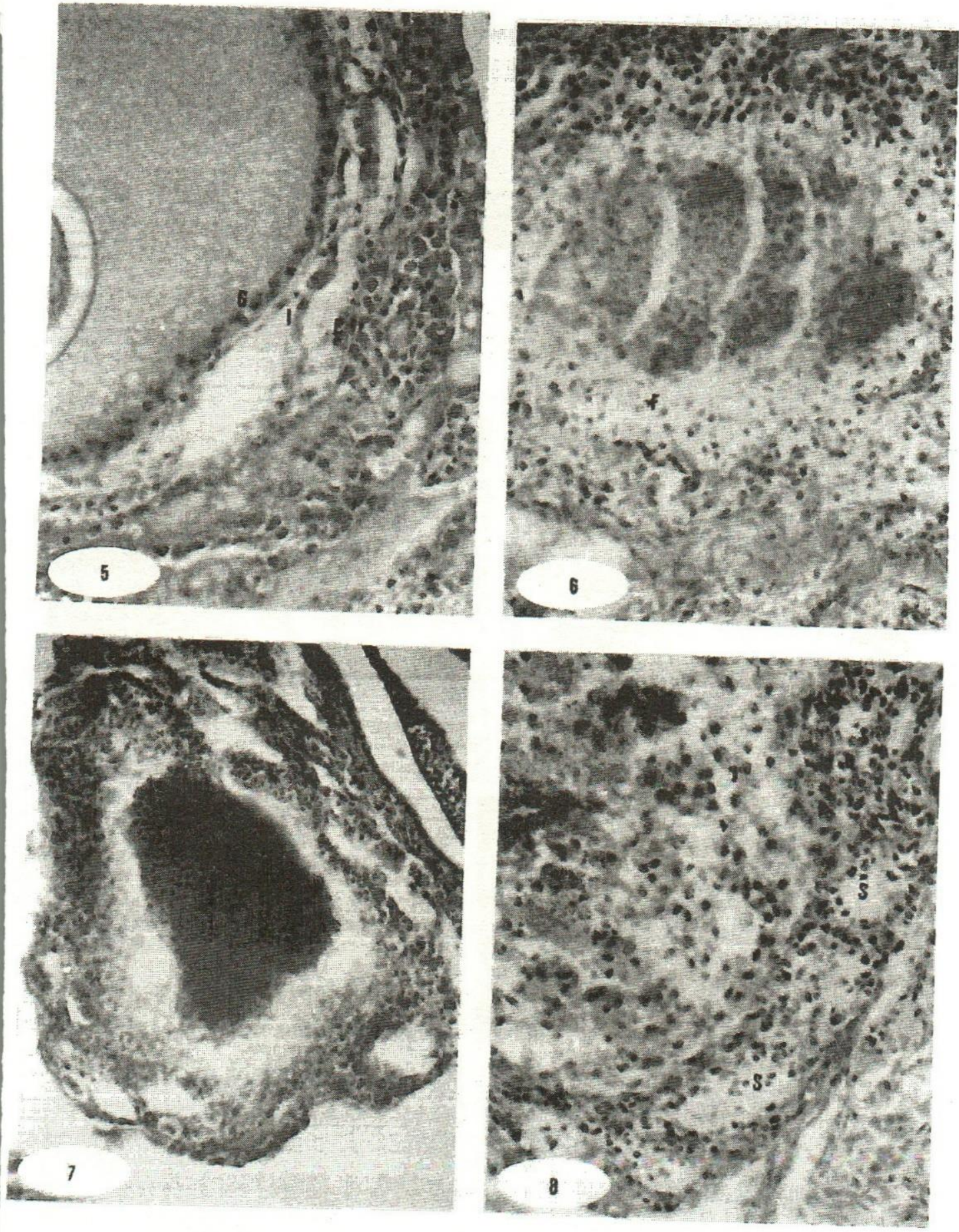

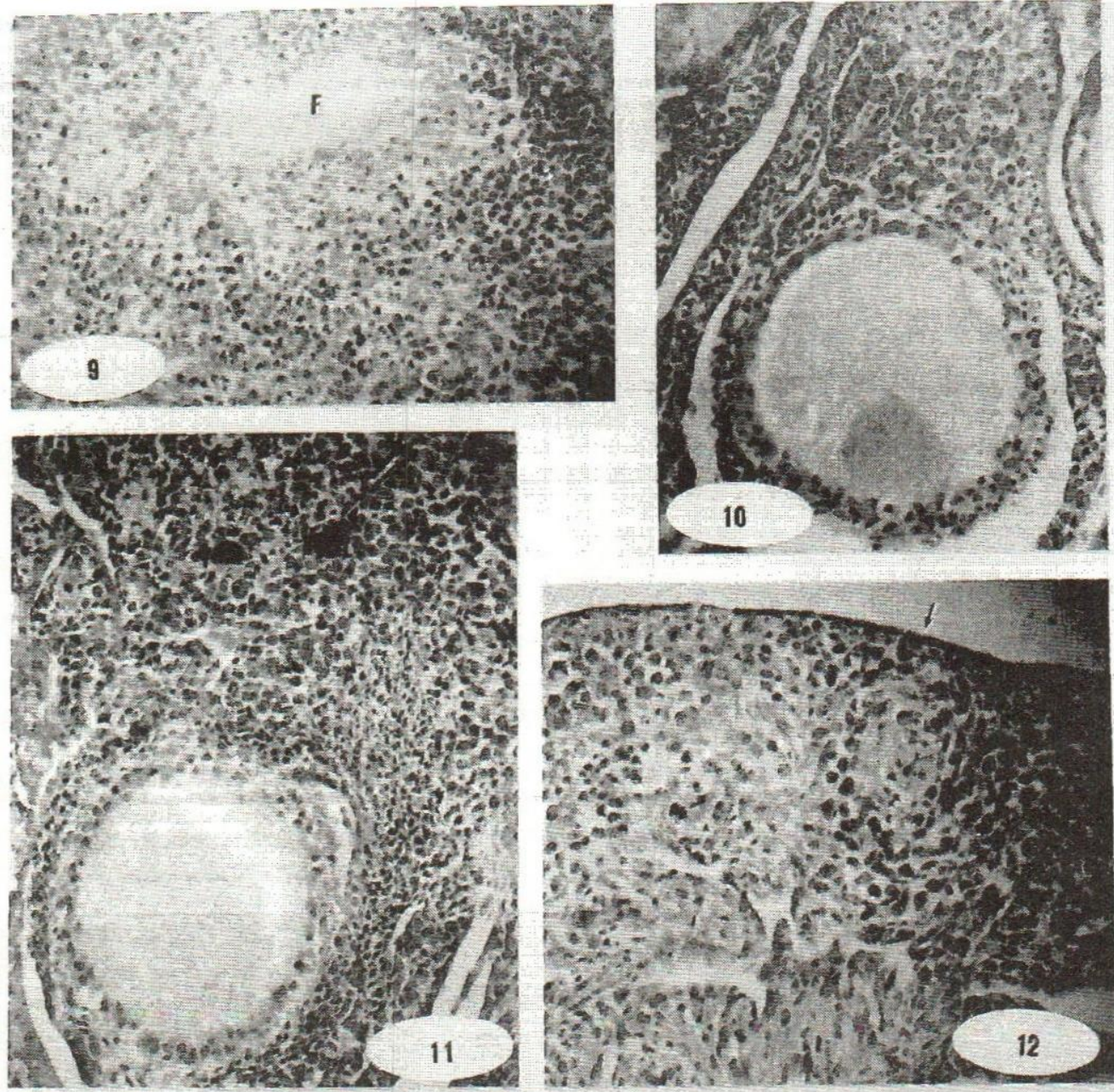

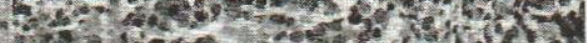

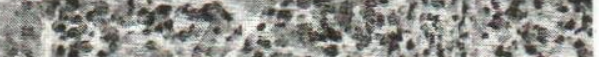

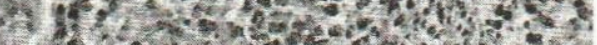

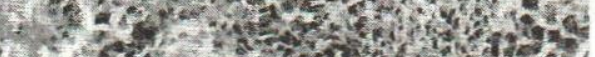

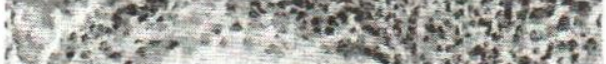
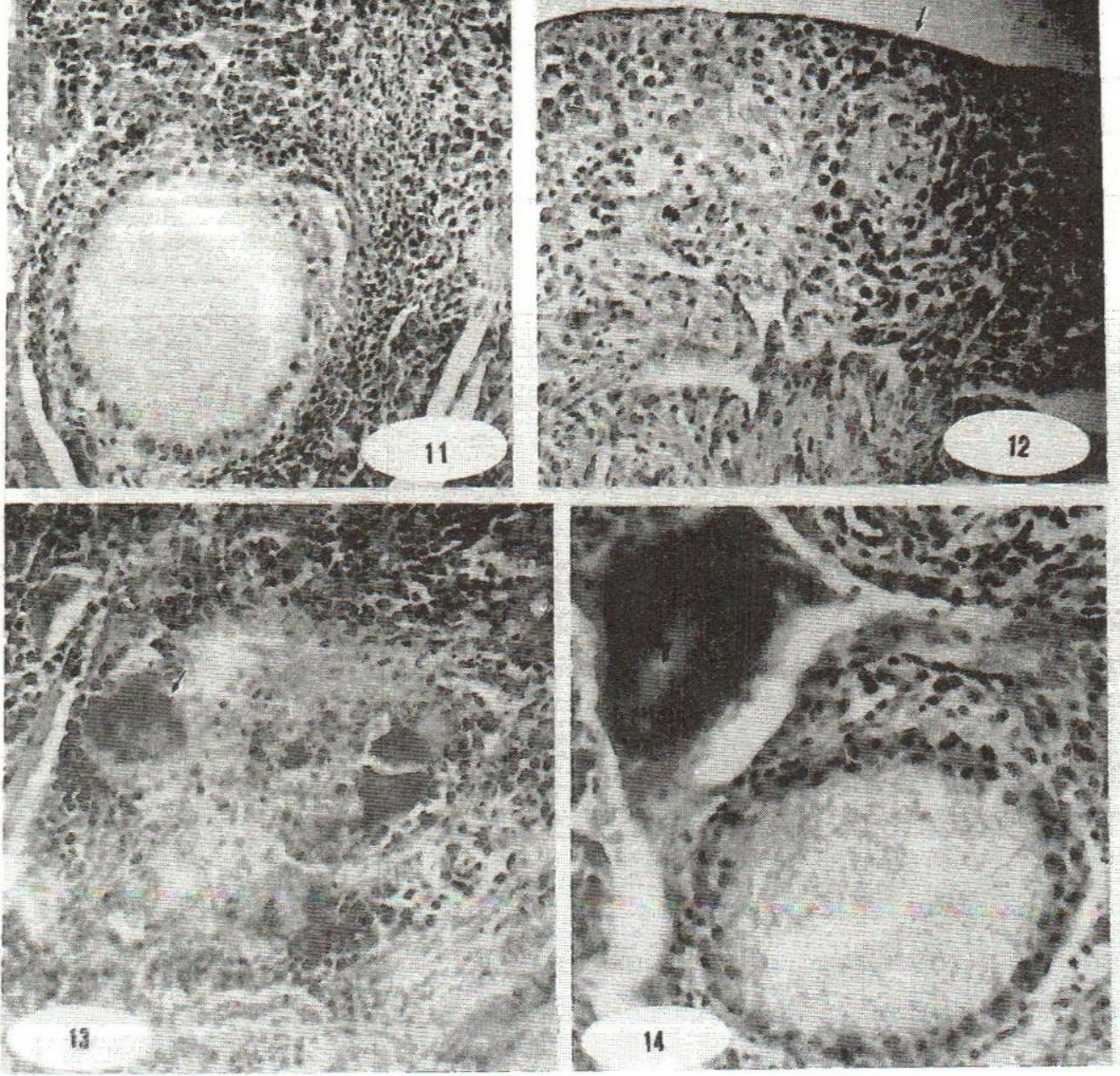
Assiut Vet. Med. J. Vol. 40 No. 79. October 1998.
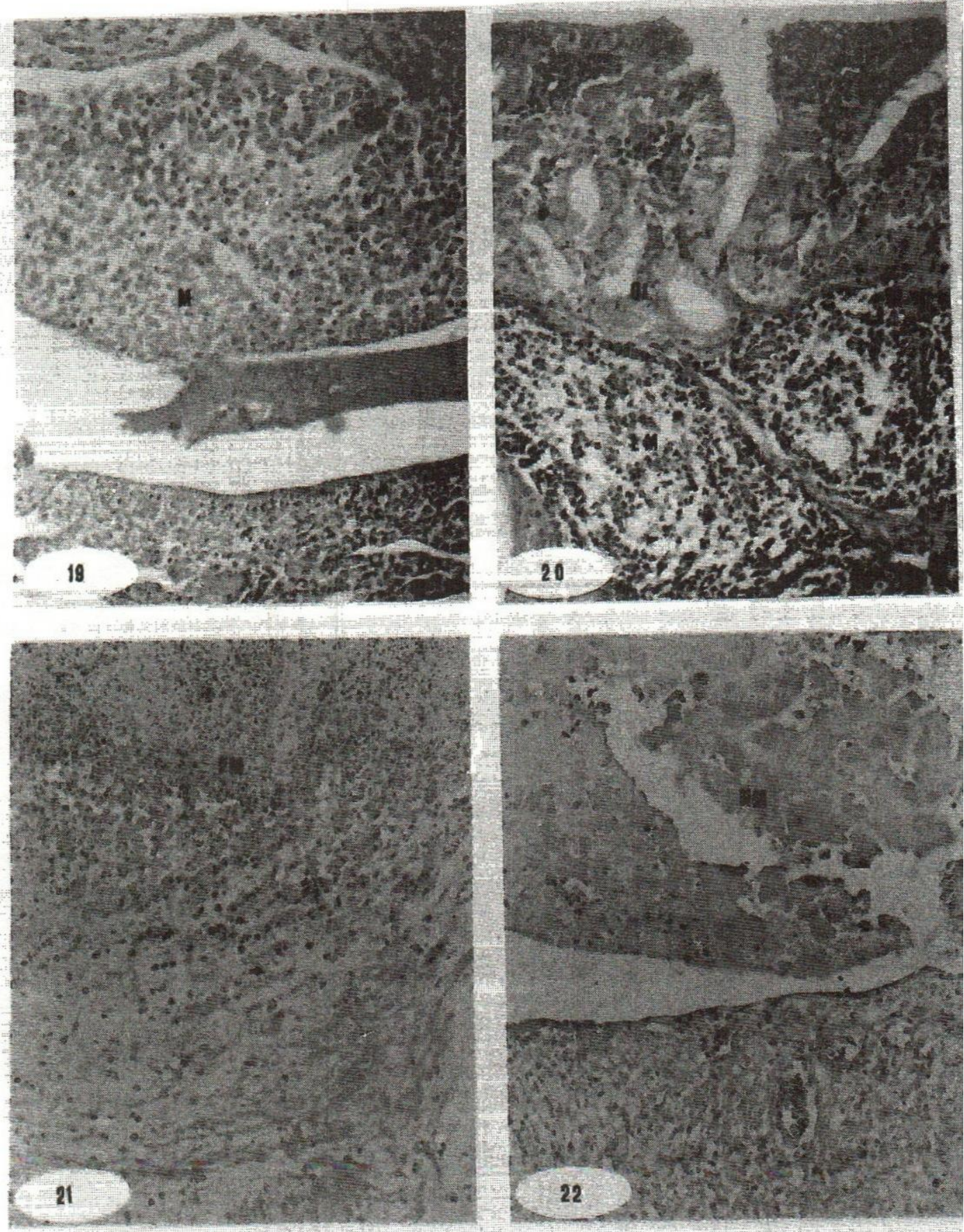